
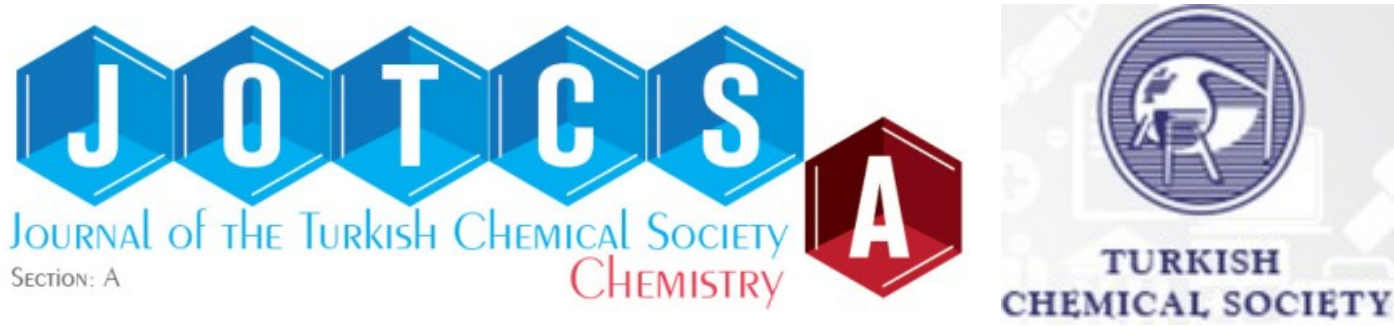

\title{
Sodium-Neutralized Sulfated Polymers as Polymeric Salt Hydrates for Thermal Energy Storage
}

\author{
Elif Adıgüzel $\triangle(D)$ and Cemil Alkan* $\triangle(D$
}

Department of Chemistry, Tokat Gaziosmanpaşa University, Tokat 60240, Turkey

\begin{abstract}
Salt hydrates are latent storage materials with exterior properties like energy storage density, availability, and cost efficiency. However, many of them have handicaps, not overcome yet, like irreversibility, corrosion, and overcooling. In this work, it is aimed to produce polymer-based salt hydrates for the first time. For this reason, some selected polymers (polyvinyl alcohol (PVA), poly(ethylene-co-acrylic acid) (PEAA) and polystyrene (PS) have been functionalized through chemical processes to impart salt clusters in the matrix consisting of some water together. For sulfonation and sodium neutralization, known procedures at molecular basis have been used, as for the characterization, FTIR was exploited. Thermal energy storage properties like phase change temperature, enthalpies, specific heat values, phase change reversibility, and total enthalpy have been determined using differential scanning calorimetry (DSC) technique. Furthermore, surface characteristics through contact angle measurements are considered as remarkable to monitor the change in the nature (hydrophobicity) of the polymeric system.
\end{abstract}

Keywords: Energy storage; phase change material; salt hydrate; sodium sulfate.

Submitted: May 14, 2020. Accepted: February 28, 2021.

Cite this: Adiguzel E, Alkan C. Sodium-Neutralized Sulfated Polymers as Polymeric Salt Hydrates for Thermal Energy Storage. JOTCSA. 2021;8(2):461-70.

DOI: https://doi.org/10.18596/jotcsa.737622.

*Corresponding author. E-mail: cemil.alkan@gop.edu.tr. Tel.: +90-3562521616; fax: +90-3562521285

\section{INTRODUCTION}

Thermal energy storage (TES) materials are widely interested due to enormous potential declared in the literature. TES is performed by holding thermal energy for later utilization. It is well known as the most yielding way of energy storage. Also it has become an advanced storage technology for sophisticated applications in thermal comfort and sensory property of textiles, protecting electronics, cooling power systems, residual heat recovery in factories, etc. It is very effective on reducing the mismatch of the sources and needs (1-4).

Thermal energy is stored and retrieved both as sensible and latent heats in physically changing systems. Specific heat capacity of materials is the case point for sensible storage. The temperature change determines charging or discharging in other words uptake or release of energy. Latent heat storage system is based on heat uptake or release during phase changing. The system stores energy isothermally because temperature is constant during phase change. Thermo-chemical energy storage reveals by breaking and reforming of molecular bonds in reversible chemical reaction. Heat of reaction determines the storage and release capacity (5-8).

Phase change materials (PCMs) are distributed mainly into two groups: organics e.g. paraffin or inorganic e.g. ice or salt hydrates like sodium sulfate decahydrate (Glauber salt, $\mathrm{Na}_{2} \mathrm{SO}_{4} .10 \mathrm{H}_{2} \mathrm{O}$ ) and calcium chloride hexahydrate $\left(\mathrm{CaCl}_{2} \cdot 6 \mathrm{H}_{2} \mathrm{O}\right)$. Some of hydrated salts as PCMs have enormously large latent heat storage density $\left(\sim 300 \mathrm{~kJ} / \mathrm{m}^{3}\right)$, low cost, and easy availability. But they are generally problematic due to their well known drawbacks like phase separation (9), sub-cooling $(10,11)$, and corrosion $(12,13)$.

For instance, $\mathrm{Na}_{2} \mathrm{SO}_{4} \cdot 10 \mathrm{H}_{2} \mathrm{O}$, may turn to a mixture of $\mathrm{Na}_{2} \mathrm{SO}_{4} \cdot 3 \mathrm{H}_{2} \mathrm{O}$ particles and $\mathrm{Na}_{2} \mathrm{SO}_{4}$ aqueous solution during heating/cooling cycles by the time. Melting point of $\mathrm{CaCl}_{2} \cdot 6 \mathrm{H}_{2} \mathrm{O}$, is at around $28{ }^{\circ} \mathrm{C}$, but 
it may not crystallize even at $\sim 0{ }^{\circ} \mathrm{C}$ if there is no nucleating agent in the system (14).

Energy storage capacities of hydrated salts are generally large. $\mathrm{Na}_{2} \mathrm{SO}_{4} \cdot 10 \mathrm{H}_{2} \mathrm{O}$ is used as a PCM because it has huge storage potential due to its high hydration number leading to considerable crystallization energy (254 J/g) (15), high thermal conductivity and low cost compared to most PCMs like paraffins. Biswas (1977) and Marks (1980) investigated the content of water during crystallization of Glauber's salt $(16,17)$. Their works showed that Glauber's salt could store 1.79 times latent energy of water.

Polymeric salt hydrates declared here is a new definition for TES materials. It means hydrated salts in a polymer backbone to form ionic crystals. The level of functionalization and neutralization in polymeric salt hydrates differs from ionomers in which the level of functionalization is about $10 \%$ at most. On the other hand, polymeric salt hydrates differ from ionized polymers. Ionization is another process just bearing ionic points in the backbone and its level is generally around $30 \%$ of the total repeating units. Ionic clusters in the ionized polymers do not accommodate hydration water. In this work, it is aimed to reach as high weight percentages of hydration in salt clusters as possible. The weight percentage of the clusters determinate the amount of energy stored and released during heating and cooling respectively. In this study, sulfonation and sodium hydroxide $(\mathrm{NaOH})$ neutralization were chosen to form polymeric salt hydrates for the aim of producing polymers with sodium neutralized sulfated group with hydrated water. When hydrated salt property is imparted to a polymeric backbone the new material will be a shape stabilized polymeric salt hydrate resulting in solution shaping property. In addition, they may have some potential for other possible applications. For example, they could be used as matrix for salt hydrates to produce compatible blends and composites for TES applications.

As polymeric salt hydrates, poly(vinyl alcohol) (PVA), poly(ethylene-co-acrylic acid) (PEAA) and polystyrene (PS) which can be processed in solution or in melt were chosen as polymeric precursor materials. They are sulfated according to the procedures similar to literature (18-21) and neutralized using $\mathrm{NaOH}$ solution. Sulfur trioxide complexes with amines such as pyridinium and triethylamine have been used extensively for the synthesis of sulfate esters of alcohols as well as other organic transformations (19). Polymeric sulfated PVA (SPVA) and sodium-neutralized SPVA (Na-SPVA), sulfated PEAA (SPEAA) and sodiumneutralized SPEAA (Na-SPEAA), and sulfated PS (SPS) and sodium-neutralized SPS (Na-SPS) were characterized by Fourier Transform Infrared (FT-IR) spectroscopy by comparison to precursor polymers. The TES property and physical properties of them were tested to reveal applicability. The changes in physical properties can be accepted as the evidence of the synthesis and therefore surface contact angles were determined.

\section{MATERIALS AND METHODS}

\section{Materials}

Polyvinyl alcohol (Sigma Aldrich, $M w=124,000$ $\mathrm{g} / \mathrm{mol}$ ), Poly(ethylene-co-acrylic acid) (Sigma Aldrich, acrylic acid $5 \mathrm{wt} \%$ ), polystyrene (Sigma Aldrich, $M w=192,000 \mathrm{~g} / \mathrm{mol}), \quad$ Sulfur trioxide (Aldrich), triethylamine (Merck), PVA (Fluka), PEAA (Aldrich), PS (Aldrich), toluene (Carlo Erba), isopropyl alcohol (Carlo Erba), dimethylformamide (DMF, Merck), $\mathrm{NaOH}$ (Sigma Aldrich), sulfuric acid (Sigma Aldrich), acetic anhydride (Sigma Aldrich), 1,2-dichloroethane (Merck) were all used as received.

\section{Methods}

Synthesis of SPVA and Na-SPVA Polymers

For the sulfonation and neutralization, common procedures as depicted in Figure 1 were used. For sulfonation, $10 \mathrm{~g}$ of sulfur trioxide-triethylamine complex was added to a solution of $10 \mathrm{~g}$ PVA in 150 $\mathrm{mL}$ of anhydrous DMF in a round bottomed flask equipped with a condenser. The mixtures were stirred at $50{ }^{\circ} \mathrm{C}$ for $48 \mathrm{~h}$. The SPVA was obtained after evaporation of the solvent under vacuum, washing the polymer with triethylamine $(15 \mathrm{~mL})$ and drying under vacuum to constant weight. Neutralization was done by using saturated solution of $\mathrm{NaOH} .87 .6 \%$ of $\mathrm{OH}$ groups of the PVA were sulfonated and sodium neutralized according to the calculations.

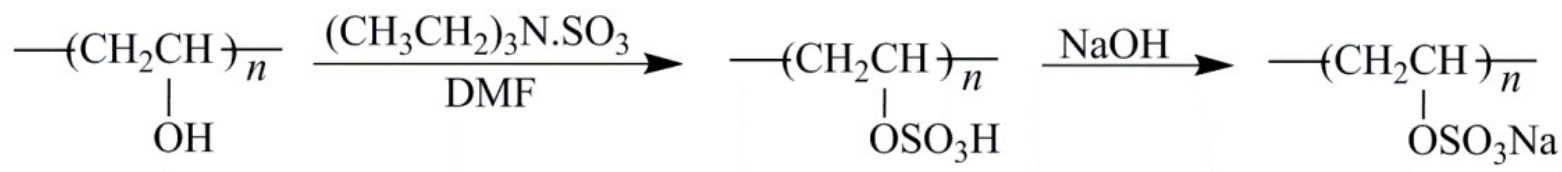

Figure 1. Synthetic scheme of SPVA and Na-SPVA polymer.

Synthesis of the SPEAA and Na-SPEAA Polymers PEAA was also sulfated using the same procedure with PVA. The only difference is that $10 \mathrm{~g}$ of sulfur trioxide-triethylamine complex was added to a solution of $10 \mathrm{~g}$ PEAA in $150 \mathrm{~mL}$ of solvent $(85 \%$ toluene-15\% isopropyl alcohol) in a round-bottomed flask with a condenser. Rigorous stirring was performed at $50{ }^{\circ} \mathrm{C}$ for $48 \mathrm{~h}$. The SPEAA was washed with triethylamine $(15 \mathrm{~mL})$ and vacuum-dried. Then, neutralization was conducted in $85 \%$ toluene-15\% isopropyl alcohol mixture using $\mathrm{NaOH}$ solution. The outline of the synthesis was depicted in Figure 2. $84.3 \%$ of $-\mathrm{CO}_{2} \mathrm{H}$ groups of the PEAA was sulfonated 
and sodium- neutralized according to the calculations.

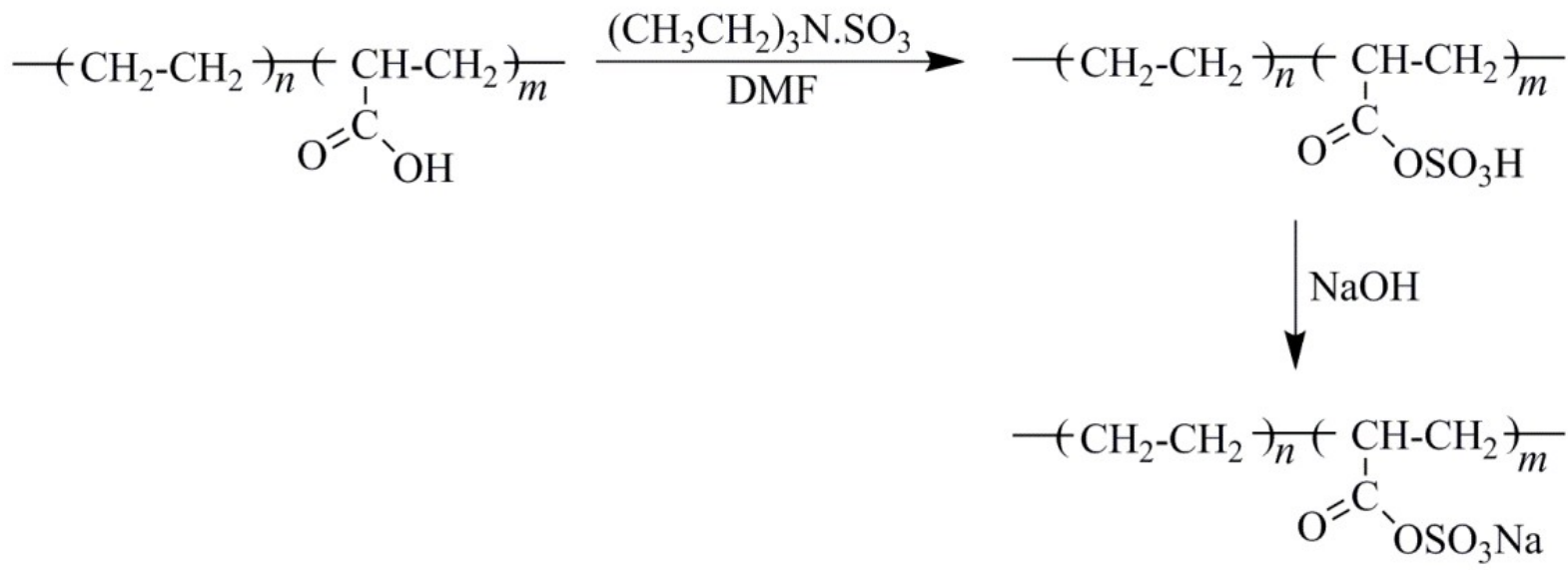

Figure 2. Synthetic scheme of SPEAA and Na-SPEAA polymers.

Synthesis of the SPS and Na-SPS polymers

$1.33 \mathrm{~mL}$ of $\mathrm{H}_{2} \mathrm{SO}_{4}$ and $2.358 \mathrm{~mL}$ of acetic anhydride were added to solution of $10 \mathrm{~g}$ of PS in $125 \mathrm{~mL}$ of dichloroethane and this mixture was rigorously stirred for $1 \mathrm{~h}$. And then the mixture was dropwise added to $2 \mathrm{~L}$ boiling water. The SPS was obtained after evaporation of the solvent under vacuum. Then the SPS was neutralized with a saturated solution of $\mathrm{NaOH}$. Figure 3 shows the synthetic scheme of SPS and Na-SPS (21). $14.7 \%$ of phenyl groups of the PS was sulfonated and sodium-neutralized according to the calculations.<smiles>CCC(C)c1ccccc1</smiles><smiles>CC(=O)OC(C)=O</smiles><smiles>CCCc1ccc(OS(=O)(=O)O)cc1</smiles>

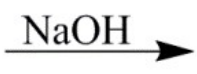<smiles>CCC(F)c1ccc(OS(N)(=O)=O)cc1</smiles>

Figure 3. Synthetic scheme of SPS and Na-SPS polymers.

\begin{abstract}
Determination of degree of sulfonation and metal neutralization

The resultant solution from the sulfonation process is stirred for $2 \mathrm{~h}$ at $50{ }^{\circ} \mathrm{C}$. Then it is transferred to deionized water. The sulfonated polymers are precipitated, filtered, and dried at room temperature as the solution obtained from filtration is used to determine the degree of sulfonation. Sulfonated polymer samples in a mixture of toluene/methanol $(1 / 9 \mathrm{v} / \mathrm{v})$ solution, with phenolphthalein indicator, are titrated with $0.02 \mathrm{M} \mathrm{NaOH}$ solution. $\mathrm{NaOH}$ solution is standardized with primary standard potassium hydrogen phthalate according to ASTM E 200-91 $(22,23)$. Due to weak acid and strong base reaction, sulfonated polymers are accepted as fully neutralized.
\end{abstract}

\section{Characterization}

TES systems should have phase-separated salt hydrate crystal domains in the matrix of the polymer since the enthalpy is born as a result of the water uptake or release from the packed crystalline structure. In polymeric salt hydrates ionic crystalline clusters were intentionally distributed in the polymer matrix with water in the cage of the crystalline parts, so that the water would be released from the packed system to the same volume.
PVA, PEAA, and PS with hydrophilic, amphiphilic and hydrophobic characters were chosen as precursor molecules, respectively. Hydrophobicity would be effective in the structure of clusters distributed in the matrix. Water was expected to come from the hydrophilic parts to the clusters when needed. To maintain homogeneity, the polymers are formed in solution by mechanical mixing. Thermophysical characteristics of prepared polymeric salt hydrates have been investigated by a differential scanning calorimeter (DSC) instrument (Netzsch-DSC 214 Polyma). Total enthalpy of the materials was calculated according to our previous studies $(24,25)$. Besides DSC is also used for $\mathrm{Cp}$ measurement of $\mathrm{Na}$ SPVA, Na-SPEAA and Na-SPS.

\section{RESULTS AND DISCUSSION}

\section{FTIR Spectroscopy Analysis of Sulfonation Processes}

Figure 4 shows FTIR spectra of PVA and its sulfated derivative (the left picture in the first row), PEAA and its sulfated derivative (the right picture in the first row), and PS and its sulfated derivative (the picture in the second row). Pristine polymers are used for comparison to sulfated derivatives. 

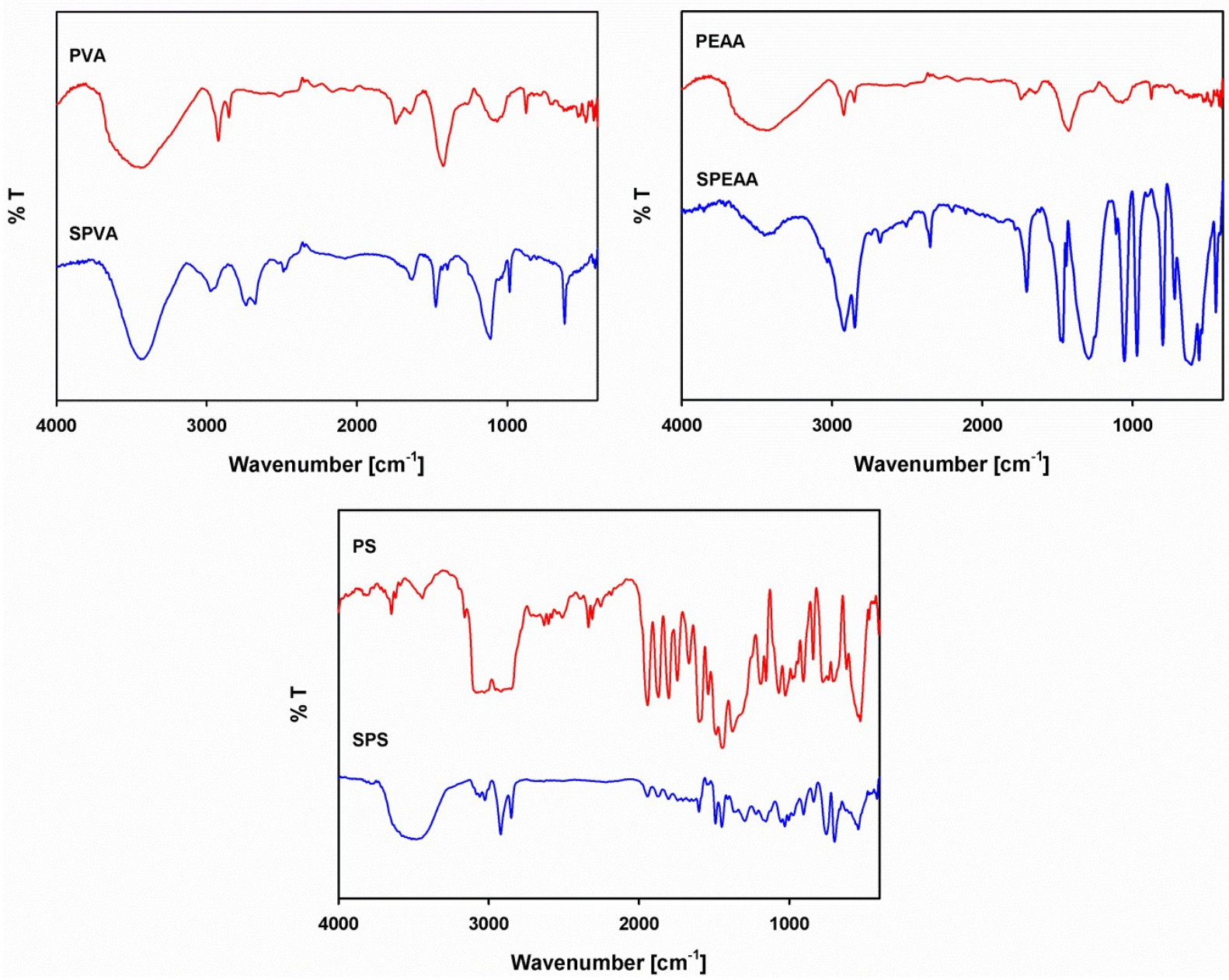

Figure 4. FTIR spectra of the pristine polymers and their sulfated derivatives.

$\mathrm{C}-\mathrm{H}$ bending peaks of PVA were observed at 1646 and $1742 \mathrm{~cm}^{-1}$ as stretching peaks were observed at around 2853 and $2922 \mathrm{~cm}^{-1}$ in the spectrum. Besides, hydrogen bonding peaks due to hydroxyl groups interactions were broad and observed between 3048 and $3720 \mathrm{~cm}^{-1}$. Also, C-H bending peaks of SPVA were observed at 1610 and $1697 \mathrm{~cm}^{-1}$ as stretching peaks were observed at around 2675 and $2732 \mathrm{~cm}^{-1}$. Moreover, hydrogen bonding peaks placed between 3166 and $3635 \mathrm{~cm}^{-1}$. These shifts were accepted as evidence of the change in the structure. In addition, the peak at around $2976 \mathrm{~cm}^{-1}$ was due to $\mathrm{C}-\mathrm{H}$ stretching peaks as $-\mathrm{OSO}_{3}$ stretching peak at $986 \mathrm{~cm}^{-1}$ were only observed in the SPVA.

$\mathrm{C}-\mathrm{H}$ stretching peaks of PEAA were observed at 2851 and $2917 \mathrm{~cm}^{-1}$ as hydrogen bonding peaks were observed at 3087 and $3697 \mathrm{~cm}^{-1}$. In addition, carboxyl stretching peaks were present at $1750 \mathrm{~cm}$ 1. Additionally, SPEAA FTIR spectrum showed C-H stretching peaks at $2851 \mathrm{~cm}^{-1}$ and $2920 \mathrm{~cm}^{-1}$. On the other hand, hydrogen bonding peaks were observed at 3254 and $3693 \mathrm{~cm}^{-1}$ after sulfonation. SPEAA polymer resulted in 954, 1054 and $3036 \mathrm{~cm}^{-1}$ stretching peaks for $-\mathrm{OSO}_{3}$ groups.
C-H stretching peaks of aromatic PS arose at 2993$3112 \mathrm{~cm}^{-1}$ as aliphatic $\mathrm{C}-\mathrm{H}$ stretching peaks were observed at 2833 and $2972 \mathrm{~cm}^{-1}$ in PS spectrum. SPS spectrum showed some differences in aromatic $\mathrm{C}-\mathrm{H}$ stretching that were at $3028 \mathrm{~cm}^{-1}$ and $3063 \mathrm{~cm}^{-1}$ and aliphatic $\mathrm{C}-\mathrm{H}$ stretching that were 2851 and $2920 \mathrm{~cm}^{-1}$. Besides, SPS showed a broad peak for hydrogen bonding at between 3227 and $3728 \mathrm{~cm}^{-1}$. Furthermore, SPS spectrum showed some extra peaks at 1152, 1186, and $3157 \mathrm{~cm}^{-1}$ in shoulder form for $-\mathrm{SO}_{3} \mathrm{H}$ groups.

\section{Thermophysical and TES characteristics of sodium neutralized sulfated polymers}

Figure 5 represents DSC thermograms of Na-SPVA, Na-SPEAA, and Na-SPS. According to the graphs, reversible phase changes of $\mathrm{Na}$-SPVA and Na-SPS were clear as Na-SPEAA did not show any phase transition. If the phase change temperatures and enthalpies were compared to the best-known sodium sulfonate material, Glauber salt, the temperatures were found as much lower. It can be explained by the extended morphology of sodiumneutralized sulfated clusters. Also, it is interesting that the enthalpy of phase changes for both $\mathrm{Na}$ SPVA and NaSPS were considerable during heating 
and cooling (Table 1). Because that the DSC was operated twice for each sample and almost completely same results were found in both run, i.e. reversibility was proven for the sodium neutralized sulfated species. The data from the graphs were tabulated in Table 1 . It was another important remark for the results that the overcooling in the polymers was reasonable.
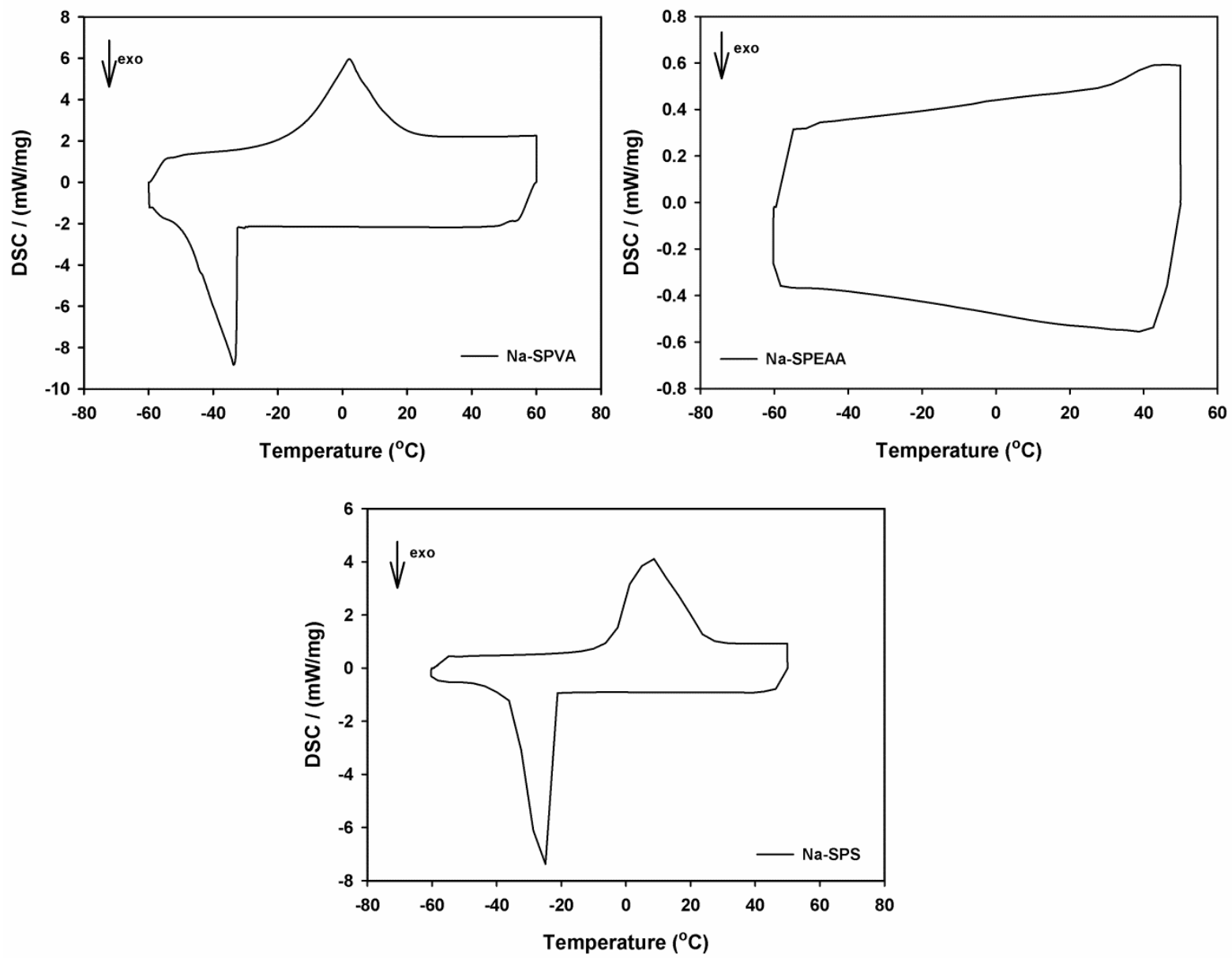

Figure 5. DSC Thermograms of sodium neutralized sulfated polymers.

Table 1. Summary of DSC data for Na-SPVA, Na-SPEAA, and Na-SPS samples phase transitions.

\begin{tabular}{llccc}
\hline Materials & Periods & Onset Temperature $\left(^{\circ} \mathbf{C}\right)$ & Peak Temperature ( $\left.{ }^{\circ} \mathbf{C}\right)$ & Enthalpy $(\mathrm{J} / \mathrm{g})$ \\
\hline Na-SPVA & Heating & -14.0 & 2.2 & 293.7 \\
& Cooling & -33.0 & -34.0 & 241.5 \\
Na-SPS & Heating & -1.2 & 1.7 & 239.9 \\
& Cooling & -16.0 & -17.0 & 211.6 \\
\multirow{2}{*}{ Na-SPEAA } & Heating & - & - & - \\
& Cooling & - & - & - \\
\hline
\end{tabular}

The reason why sulfonated and sodium-neutralized sulfonated poly(ethylene-co-acrylic acid) copolymer does not show phase transition behavior is that acrylic acid component is present in polymer structure at $5 \%$. This low rate could not form ionic clusters when sulfonated and neutralized with sodium. For this reason, it could not contain water and could not release it at a certain temperature.

$\mathrm{Cp}$ versus temperature relationships for Na-SPVA, $\mathrm{Na}-\mathrm{SPEAA}$, and Na-SPS were shown in Figure 6. As expected the $\mathrm{Cp}$ around the phase change abruptly increased (theoretically infinite). 

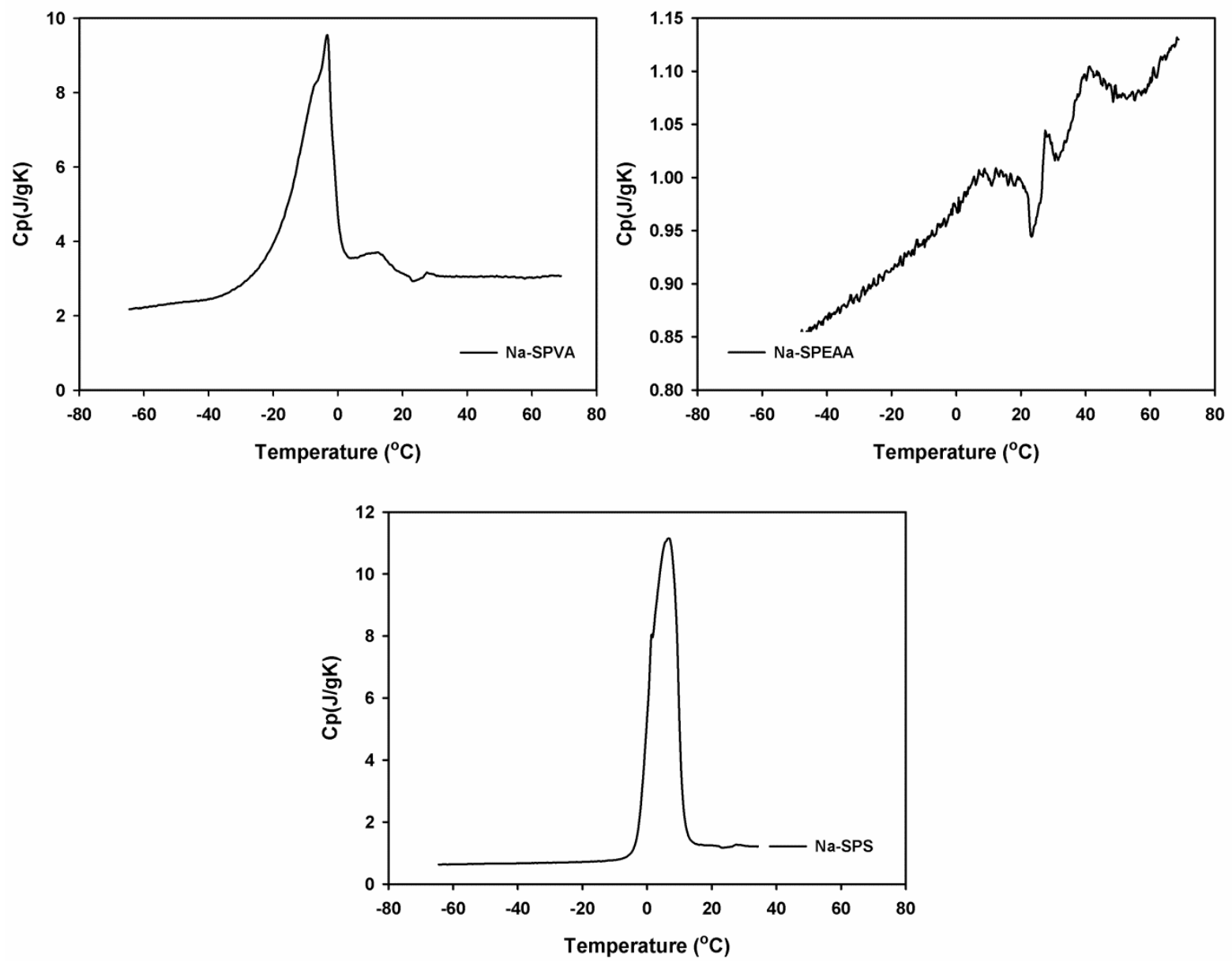

Figure 6. $\mathrm{Cp}$ versus temperature relationships for $\mathrm{Na}$-SPVA, Na-SPEAA, and $\mathrm{Na}-\mathrm{SPS}$ samples

Figure 7 shows total enthalpy curves upon temperature increase for Na-SPS. According to the curves $1278 \mathrm{~J} / \mathrm{g}$ energy was stored between $-60{ }^{\circ} \mathrm{C}$ and $60{ }^{\circ} \mathrm{C}$ as a total of latent and sensible heat. Most of this energy is latent-based.

Total enthalpy curves have been studied in two runs in order to prove reversibility. Reversibility is one of the main problems of salt hydrate systems. It is well known that active thermal storage systems using salt hydrates showed irreversible working. The curve for both runs resulted in the same formation proving reversibility. Fortunately, the phase transition temperature was very low for Na-SPVA and therefore it probably resulted in the continuous presence of the water in the clusters when released.

The curves for Na-SPEAA showed no phase transitions and total enthalpy stored was due to sensible heat storage capability. According to the graph, Na-SPEAA polymer stored $14 \mathrm{~J} / \mathrm{g}$ of thermal energy between $-60{ }^{\circ} \mathrm{C}$ and $40{ }^{\circ} \mathrm{C}$ reversibly.

At last, Na-SPS polymer stored and released $537 \mathrm{~J} / \mathrm{g}$ of energy as sensible and latent heat between -60 ${ }^{\circ} \mathrm{C}$ and $40{ }^{\circ} \mathrm{C}$ reversibly. Majority of this heat is due to phase changing. The two runs repeated the curves and proved reversibility. 

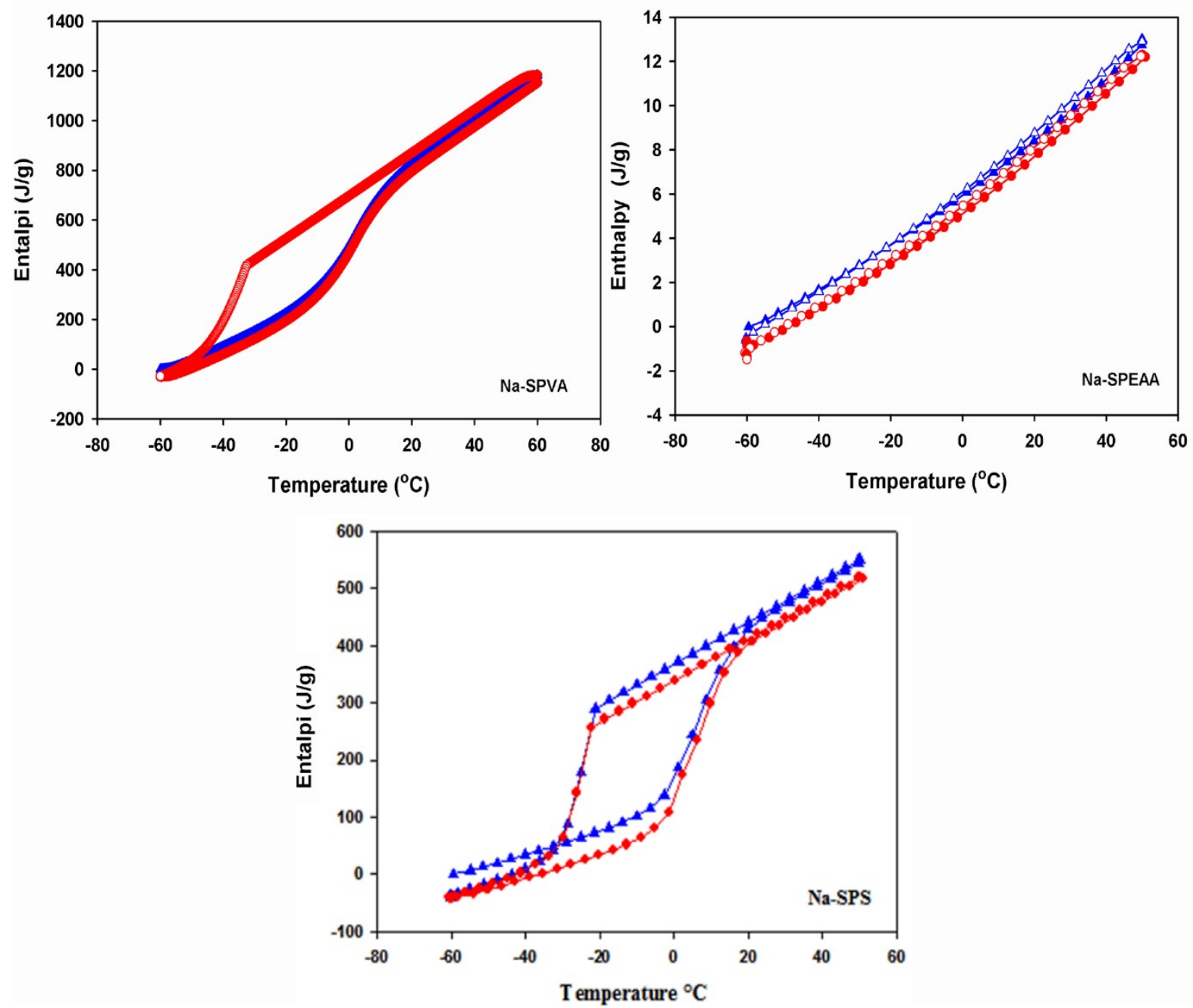

Figure 7. Total enthalpy curves for Na-SPVA, Na-SPEAA, and Na-SPS for 2 runs.

Surface character of the SPVA, SPEAA, and SPS polymers

Chemical changes performed on pure polymers were expected to result in a change in hydrophobicity compared to the pristine polymers used, as sulfated materials are highly hygroscopic. Sulfuric acid itself was one of the best moisture absorbent materials and sulfonation induces modified polymers hydrophilicity. Contact angle measurement is the best way to determine the change in hydrophilic property. Figure 8 shows the photographs of the water droplets on the polymer samples, while Table 2 shows the contact angle values (right side, left side and mean).

According to contact angle measurements it was found that sulfonation had always increased surface wettability. The least effected one was the most hydrophobic one, PS. 
PVA

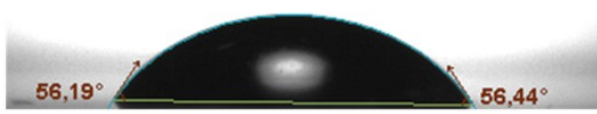

PEAA

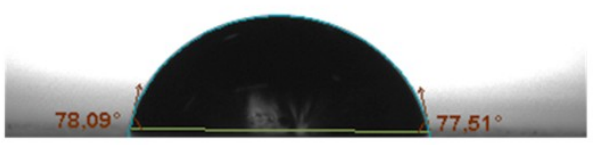

PS
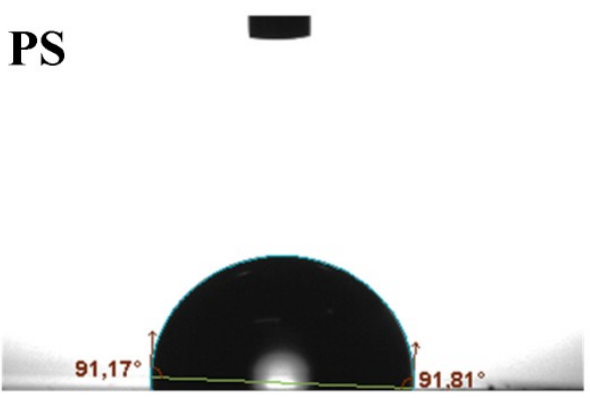

SPVA

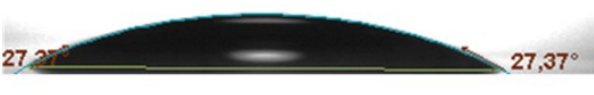

SPEAA

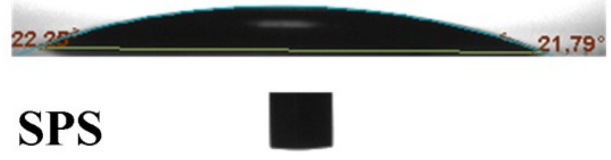

Figure 8. Contact angles of pristine polymers and SPVA, SPEAA, and SPS.

Table 2. Contact angles of the pristine polymers and Na-SPVA, Na-SPEAA, and Na-SPS with water (from both left and right sides)

\begin{tabular}{llll}
\hline Material & $\begin{array}{l}\text { Contact } \\
\text { angle (left) }\end{array}$ & $\begin{array}{l}\text { contact } \\
\text { angle (right) }\end{array}$ & $\begin{array}{l}\text { contact angle } \\
\text { (mean) }\end{array}$ \\
\hline PVA & 56.19 & 56.44 & 54.32 \\
SPVA & 27.27 & 27.37 & 27.32 \\
PEAA & 78.09 & 77.51 & 77.80 \\
SPEAA & 22.25 & 21.79 & 22.02 \\
PS & 91.17 & 91.81 & 91.49 \\
SPS & 88.20 & 88.94 & 88.57 \\
\hline
\end{tabular}

\section{CONCLUSIONS}

Some newly defined polymeric salt hydrates have been produced and tested for their thermal energy storage characteristics for the first time. The work was inspired from the polymeric electrolytic batteries. The ionic clusters were operated for water packing and serving as hydrated salt for TES instead of electronic conduction. To start with the sulfonated polymeric salt hydrates at least the phase change ability was achieved. Although they were not as effective as the inspiration sources, they could be developed to reach better performance characteristics in the following studies.
PVA, PEAA, and PS were chosen as polymeric compounds with decreasing hydrophobicity character. However, PVA and PS were converted to sulfated species trapping water in the ionic clusters as PEAA was somehow different and not trapping water in the structure. Therefore, it was to say that PEAA was not a suitable material for TES operations as the other polymeric salt hydrates. The resultant of sulfonation in $\mathrm{Na}$-SPEAA was somehow different compound than a sulfated species and neutralized version was also something else than a sulfonate with water to be used as an energy storage source. 
Enthalpies of the Na-SPVA and Na-SPS were very satisfactory although the phase transition temperatures decreased drastically. Actually, the materials with phase change ability were potential candidates for their working temperature in some applications. On the other hand, probably the decrease could be prevented by some further studies and better polymeric salt hydrates can be prepared.

\section{ACKNOWLEDGEMENTS}

The author would like to acknowledge the support to INOTES project in the scope of EU ERA NET New Indigo Program funded by Scientific and Technological Research Council of Turkey (TÜBiTAK, Project No: 114M121).

\section{REFERENCES}

1. Nazir H, Batool M, Osorioc FJB, Isaza-Ruiz M, Xu X, Vignarooban K, Phelan P, Inamuddin, Kannan AM. Recent developments in phase change materials for energy storage applications: A review. Int J Heat and Mass Trans 2019;129:491-523. https://doi.org/10.1016/j.ijheatmasstransfer.2018.09 .126

2. Zhang N, Yuan $Y$, Cao $X, D u ~ Y$, Zhang Z, Gui $Y$. Latent Heat Thermal Energy Storage Systems with Solid-Liquid Phase Change Materials: A Review. Adv Eng Mater 2018;20(6):1-30. https://doi.org/10.1002/ adem.201700753

3. Du K, Calautit J, Wang Z, Wu Y, Liu H. A review of the applications of phase change materials in cooling, heating and power generation in different temperature ranges. Appl Energ 2018;220:242-273. https://doi.org/10.1016/j.apenergy.2018.03.005

4. Efimova A, Pinnau S, Mischke M, Breitkopf C, Ruck M, Schmid P. Development of salt hydrate eutectics as latent heat storage for air conditioning and cooling. Thermochim Acta 2014;575:276-278. https://doi.org/10.1016/j.tca.2013.11.011

5. Cunha JP, Eame P. Thermal energy storage for low and medium temperature applications using phase change materials-A review. Appl Energ 2016;177:227-38.

https://doi.org/10.1016/j.apenergy.2016.05.097

6. Su W, Darkwa J, Kokogiannakis G. Review of solidliquid phase change materials and their encapsulation Technologies. Renew Sust Energ Rev 2015;48:373-91.

https://doi.org/10.1016/j.rser.2015.04.044

7. Xu B, Li P, Chan C. Application of phase change materials for thermal energy storage in concentrated solar thermal power plants: A review to recent developments. Appl Energ 2015;160:286307. https://doi.org/10.1016/j.apenergy.2015.09.016

8. Huang J, Wang $T$, Zhu $\mathrm{P}$, Xiao J. Preparation, characterization, and thermal properties of the microencapsulation of a hydrated salt as phase change energy storage materials. Thermochim Acta 2013;557:1-6.

https://doi.org/10.1016/j.tca.2013.01.019

9. Cabeza LF, Svensson G, Hiebler S, Mehling $H$. Thermal Performance of Sodium Acetate Trihydrate Thickened with Different Materials as Phase Change Energy Storage Material. Appl Therm Eng 2003;23:1697-704. https://doi.org/10.1016/S13594311(03)00107-8

10. Zhang $Y$, Zhou G, Lin $K$, Zhang Q, Di $H$. Application of Latent Heat Thermal Energy Storage in Buildings: State-of-the-Art and Outlook. Build Environ 2007;42(6):2197-209. https://doi.org/10.1016/j.buildenv.2006.07.023

11. Gök Ö, Yilmaz MÖ, Paksoy HÖ. Stabilization of Glauber's salt for latent heat storage online.. Proceedings of the 10th International Conference on Thermal Energy Storage, ECOSTOCK. June31 May - 22006. Available from:

http://intraweb.stockton.edu/eyos/energy_studies/ content/docs/FINAL_PAPERS/4B-4.pdf

12. Cabeza LF, Illa J, Roca J, Badia F, Mehling $\mathrm{H}$, Hiebler S. Immersion corrosion tests on metal-salt hydrate pairs used for latent heat storage in the 32 to $36^{\circ} \mathrm{C}$ temperature range. Mater Corrosion 2001;52(2):140-6. https://doi.org/10.1002/15214176(200102)52:2<140::AID-MACO140>3.0.CO;2-R

13. Cabeza LF, Roca J, Nogués $M$, Mehling $H$, Hiebler $\mathrm{S}$. Immersion corrosion tests on metal-salt hydrate pairs used for latent heat storage in the 48 to $58{ }^{\circ} \mathrm{C}$ temperature range. Mater Corrosion 2002;53(12):902-7.

https://doi.org/10.1002/maco.200290004

14. Riffat S, Mempouo BM, Fang W. Phase change material developments: a review. Int J Ambient Energ 2013;36(3):102-15.

https://doi.org/10.1080/01430750.2013.823106

15. Saito A, Okawa S, Shintani T, Iwamoto R. On the heat removal characteristics and the analytical model of a thermal energy storage capsule using gelled Glauber's salt as the PCM. Int J Heat and Mass Trans 2001;44:4693-701.

https://doi.org/10.1016/S0017-9310(01)00113-2

16. Biswas DR. Thermal energy storage using sodium sulfate decahydrate and water. Sol Energ 1977;19:99-100.

https://escholarship.org/uc/item/59x1d2xv 
17. Marks S. An investigation of the thermal energy storage capacity of Glauber's salt with respect to thermal cycling. Sol Energ 1980;25:255-8. https://doi.org/10.1016/0038-092X(80)90332-1

18. Manikowski A, Koziol A, CzajkowskaWojciechowska E. An alternative route for fondaparinux sodium synthesis via selective hydrogenations and sulfation of appropriate pentasaccharides Carbohydr Res 2012;361,155-61

19. Nair V, Bernstein S. A convenient procedure for the preparation of triethylamine-sulfurtrioxide Organic Prep Proced Int, 1987;19:6,466-7. DOI: $10.1080 / 00304948709356213$

20. Gilbert EE. The Reactions of Sulfur Trioxide, and Its Adducts, with Organic Compounds. Chem Rev 1962;62(6):549-89. DOI: 10.1021/cr60220a003

21. Alkan C, Aras L. Miscibility of polystyrene-based ionomers with poly(2,6-dibromo-1,4phenylene oxide) J Appl Polym Sci 2001;82:3558-67. https://doi.org/10.1002/app.2218
22. Piccioni F, Giorgi I, Passaglia E, Ruggeri G, Aglietto M. Blending of styrene-block-butadieneblock-styrene copolymer with sulfonated vinyl aromatic polymers Polm Int 2001;50:714-21. https:// doi.org/10.1002/pi.692

23. ASTM-E200-91, Standard Practice for Preparation, Standardization, and Storage of Standard and Reagent Solutions for Chemical Analysis, 1991.

24. Özkayalar S, Adıgüzel E, Alay Aksoy S, Alkan C. Reversible color-changing and thermal-energy storing nanocapsules of three-component thermochromic dyes, Mater Chem and Phys $2020 ; 252,123162$.

https://doi.org/10.1016/j.matchemphys.2020.123162

25. Alkan C, Günther $E$, Hiebler $S$, Himpel $M$. Complexing blends of polyacrylic acid-polyethylene glycol and poly(ethylene-co-acrylic acid)polyethylene glycol as shape stabilized phase change materials. Energ Conver Manage. 2012;64:364-70.

https://doi.org/10.1016/j.enconman.2012.06.003 